\title{
Educational course 'Basics of working with fans' as a factor in the objectification of perception of the 2018 FIFA World Cup and football fans in Russia
}

\author{
Dihor, Victoria A. ${ }^{a}$; Serova, Nina B. ${ }^{a}$ and Narkhov, Dmitry Yu ${ }^{b}$. \\ ${ }^{a}$ Department of service and health technologies, Institute of Physical Culture, Sports and \\ Youth Policy, Ural Federal University named after B.N.Yeltsin, Russia, ${ }^{\mathrm{b}}$ a Department of \\ Organizing Youth Work, Institute of Physical Culture, Sports and Youth Policy, Ural \\ Federal University named after B.N.Yeltsin, Russia
}

\begin{abstract}
The FIFA 2018 World Cup is a significant event for Russian society. Ministries carry out various campaigns to promote football in the country. The Russian society of sociologists conducted a survey (4703 respondents) to understand the attitude to the Championship. Further, the teachers of the Ural Federal University conducted a survey of the attitude to football fans. Scientists have found that over the past 7 years, citizens have become more positive about fandoms, but there is of lack of objective information. To solve this problem, teachers at the Institute of physical culture of the Ural Federal University have developed a special course 'Basics of working with the fans'. The course is designed for students, postgraduates and teachers of physical education departments at universities as well as stewards and volunteers. Since September 2017, 118 students have been trained in this course. The course consists of two parts: theoretical - describing the types of fans, information about the differences between fans from different countries; practical - reviewing the real situations of interaction with fans, communicating with Russian and foreign fans. Classes are conducted by a sports psychologist who studies football fans for 8 years.
\end{abstract}

Keywords: the psychology of football fans, the perception of the world championship. 


\section{Introduction}

On the eve of the World Cup 2018 in Russia, various activities for the promotion of football have been carried out. For example, in each city-participant the stadiums are being reconstructed and/or refurbished, volunteers conduct lessons at schools and universities, famous athletes talk about their successes and local football teams organise charity matches. Such a set of diverse events is aimed not only at informing Russians about the event, but also at psychological training of citizens.

It is natural that the administration of a city-participant carries out large-scale preparation: infrastructure is changed, new roads, stadiums and training sights are built. Special attention is given to the service sector: employees of hotels, restaurants and museums are taught English and receive special training.

Such a large-scale training does not take into account only the attitude of citizens to the World Cup. In social networks, there are many negative reviews of citizens, most are afraid of abrupt changes and do not understand what to expect. Citizens are especially afraid of the arrival of 'inadequate fans' which can act violently in the streets. It is logical that such stereotypes are formed by the media. In 2016, the author of the article conducted a content analysis of the most popular Russian newspapers: 'Komsomolskaya Pravda', 'Izvestia', 'Arguments and facts' [See: 4.]. Articles about fans written from 2012 to 2016 were analysed. Having searched the official websites of selected newspapers for the phrase 'football fan',it was found out that it was mentioned 603 times: 10 - "Komsomolskaya Pravda"; 427 - "Arguments and Facts"; 166 - "Izvestia". The largest number of publications was in 2010, 2012 and 2014, which is associated with the European and World Cup. About 300 articles were devoted to the fans. Most of them described a fight with the police, football players or between firms, only $10-15 \%$ is telling us about the 'law on fans' or about the original support team, interesting banners and football views. There is a considerable preponderance of negative information about fans. Often in articles the word 'fan' became synonymous with words, like 'zealot', 'a bully', 'inadequate', 'a herd' or 'uncontrolled crowd'. In these articles, the representative of fan movement is described as a young man at the age of 18-28, often without a degree, with pronounced aggressiveness, intolerance towards others, inability to control himself as well as reduced intelligence. In addition, in such articles there are negatively colored adjectives that characterize fans, such as "dangerous", "uncontrolled", "stupid", "aggressive", "inhuman", "evil", etc. Thus, today's popular Russian media create a negative image of Russian fans, which forms stereotypes for society and then a certain model of behavior.

The results revealed the problem of the lack of objective information, which can contribute not only to the negative attitude to the fans, but also to the World Cup as a whole. The study was carried out to find objective information sources, fan sites and sections on the 
websites of the football clubs to find anything failed. It is logical that for an ordinary citizen which is not specifically interested in finding objective information is extremely difficult.

Next, we looked at the results of two surveys done among citizens: 1 - analysis of the perception of The World Cup; 2 - dynamics of attitude to football fans and the phenomenon of fandom (the survey was conducted twice: in 2010 and in 2017). At the end, a brief description of the educational course 'Basics of working with fans' wil be given, the aim of which is to form an adequate attitude of society to the World Cup.

\section{Methodology and results of the study}

The Russian Society of Sociologists has developed a questionnaire to identify the attitude of citizens to the World Cup. It consists of 29 questions, including 10 questions about socio-demographic information. 8 questions, like 'do you consider yourself a football fan?', are aimed at identifying interest in football. 11 questions are devoted to the relation to the World Cup 2018. Respondents are invited to express their opinion on the organization and the consequences, as well as to indicate the degree of their participation in the event.

The study took part in 4500 questionnaires plus paper unforgettable in the database: 300 from Tver, 90 - from Moscow and 50 - in a separate database from Ufa and St. Petersburg. In total, 4921 quality profiles of what? were collected. The sample of the study was 6,300 people: $59.2 \%$ women and $40.8 \%$ men [See: 12.]. All respondents were students and the vast majority of participants were between the ages of 18 and $21(82.3 \%)$.

We will look at the overall results.

First, a one-dimensional distribution of the results.

$55.8 \%$ of the informants are not interested in professional football. So, more than half of the respondents learn about The World Cup not from sports articles, but only from the news. Probably, they might adopt a negative attitude to the mega-event. The data confirm the hypothesis the results of the response to the question about attending football games: $68,9 \%$ were in the stadium only once, only $8.8 \%$ regularly attend matches and razorutsya in football.

Not all informants consider themselves to be football fans: $16.8 \%$ could call themselves fans. It is logical that this category of respondents will be spectators at the World Cup.

Despite the low interest in football, $53.6 \%$ of respondents positively relate to of the World Cup. The most popular positive aspects about this event mentioned by the respondents are: infrastructure development (new facilities, tourism and improvement of living conditions) $92.8 \%$; growth of Russia's authority in the world $-48.6 \%$. Also, $10 \%$ of respondents noted 
the spread of patriotic feelings in the country. Thus, these results indicate a positive attitude of citizens to the upcoming mega-event.

The respondents believe that the most negative consequences of the 2018 World Cup are: large financial costs $-50.9 \%$; mass riots of fans $-47.6 \%$; the risk of terracotta $-43.7 \%$. Such results indicate the presence of fear of being unsafe: respondents fear for their lives in advance. Perhaps, that is why only $25.4 \%$ of the respondents plan to attend the World Cup matches (13.4\% - as spectators; $12.2 \%$ - as volunteers).

Next, we will focus on the distribution of results based on the gender of respondents.

It is natural that girls are less interested in professional results (only 37.3\% against $54.3 \%$ in men). However, despite this, women are a little more positive $(54.5 \%)$ about the World Cup than men $(52.4 \%)$.

It is interesting to mention that women $(51.9 \%)$ are more likely to fear mass unrest among fans than men by $10 \%$. This is probably why such a low number of women attend football matches. Only $9.8 \%$ of the surveyed women (18.4\% of men) are planning to attend The World Cup as spectators. However, $13.6 \%$ of women and only $10.2 \%$ of men want to be volunteers. This result confirms the hypothesis of psychologists about the increased level of altruism in girls.

We will finish the analysis of the results on the two-dimensional distribution, taking into account the university majors the respondents did or do at universities. $26,4 \%$ chosethe humanities, $24 \%$ - technical subjects, $17,1 \%$ - economic, 9,7\% - natural sciences and information technologies, 9,6\% - physical education, 2,1\% - medicine, 0,8\% - military service, $0,5 \%$ - art.

Of those surveyed, $33.3 \%$ of the students who consider themselves football fans do military service, $24.8 \%$ of the students of physical education, $16.1 \%$ do a degree in Humanities. Representatives of artistic professions (8.3\%) are the least likely to treat themselves to fans. The results confirmed our expectations. We will note that military people and sportsmen are the most involved in interaction with fans.

Summing up, the results of the survey of the Russian Society of Sociologists, we note the low interest of students in professional football, but a positive attitude to the event in Russia. Regardless of gender and chosen major, the majority of respondents consider the mass riots of fans to be the most dangerous consequence of the Championship.

After the study of the perception of The World Cup, we will focus more on the perception of the fans.

A questionnaire (8 questions) was compiled at the Institute of Physical Education, Sports and Youth Policy. The study was conducted in 2010 and 2017. The aim of the study was 
not only to understand the attitude towards fans, but also to trace the dynamics during 7 years.

In 2010, the study involved 66 respondents, all students of the Ural Federal University [See: 7.]. In 2017, the number of participants increased to 576 people (students of various higher educational institutions in the region).

Let's start with the results that not much has changed since 2010:

1. The overwhelming majority are positive about sports (76.5\% in $2010,88 \%$ in 2017).

2. Most respondents are neutral to the phenomenon of football fandom (in $2010-61.7 \%$, in $2017-60 \%)$.

3. Most football fandom is associated with full stadiums of fans (in $2010-50 \%$, in $2017-$ $59 \%)$.

4. The respondents consider "drunk and aggressive fights of fans" to be the main disadvantage of football fandom (in $2010-88 \%$, in $2017-94.4 \%$ ).

Moving on to the most noticeable differences:

1. In 2010, respondents believed that fans are a little afraid (50\%) and then either despise $(20.5 \%)$ or ignore $(20.5 \%)$. In 2017 , significantly more respondents chose the approval and support option (in $2010-9 \%$; in $2017-35 \%$ ). Such results may indicate the effectiveness of interventions and awareness-raising activities.

2. If in 2010, the majority of respondents $53 \%$ of respondents believed that the phenomenon of football fandom is waiting for "transformation into an inadequate herd" (53\%), now there are only $30 \%$.

Such results emphasize the general positive attitude and the need to educate people about football fans.

To solve this problem, the Institute of Physical Education, Sport and Youth Policy at the Ural Federal University has developed the first in Russia training course 'Basics of working with the fans' and published a textbook 'Principles of psychology of football fans'. From September 2017 to January 2018, 118 students which do their degrees in 'Service and 'Physical Education' took the course.

The course is divided into two parts [See: 6.].

The theoretical block forms the basic knowledge about fans and includes five blocks:

1. The evolution of football fandom [See: 10.].

2. Football fans as a social active group. Classification and structural organization [See: $13]$. 
3. Specific features of fans in different countries [See: 1, 2.].

4. Psychological portraits of football fans: personal features [See: $3,8,11$.$] .$

5. Stereotypes of public perception and features of self-perception of football fans [See: 9.].

6. A study of the possibilities of self-regulation of football fans [See: 5.].

The task of the practical block is to teach students the psychological mechanisms of effective interaction with fans. In the classroom, students solve real cases, communicate with fans from Russia and other countries (Portugal, Germany, Brazil, Serbia, etc.) This section also includes five areas:

1. Establishing contact with the fans.

2. Mechanisms for predicting the behavior of fans on the basis of rapid diagnostics.

3. Hotbeds of risk: schemes for identifying fans requiring special attention.

4. Features of work with the fans, being in altered state: alcohol, drugs, severe emotional stress.

5. Features of group interaction in emergency situations.

6. Psychological methods of work with manifestations of inadequate emotional reactions.

Approbation of the course

Students noted the relevance of the course, visibility and practice-oriented approach. Before doing this course, the majority of students had no sufficient knowledge about fans and considered them to be dangerous and inadequate.

Prospects of the educational course 'Basics of working with fans'

The staff of the Institute of Physical Education, Sport and Youth Policy at the Ural Federal University are planning to include this course in the curriculum of Russian Federal universities, to develop and hold a series of events Providensky about the characteristics of football fans. At the moment, the Rector of Ural Federal University has sent official letters to the Minister of Sport and Minister of Education of the Sverdlovsk region.

The development and implementation of the Russian educational system contributes to the formation of a more objective perception of both football fans and the World Cup as a whole. The Russians who are already positive about the sports event will be able to attend football matches more often because they will be prepared for effective interaction with football fans. 


\section{References}

Brimson D. (2000). Barmy Army: The Changing Face of Football Violence, 288.

Brimson D. (1999). The Crew, 292.

Gizullina A.V., Dihor V.A. (2015) Psychological aspects of the perception of football fans. Psychological theory and practice-management, 33-37.

Dihor V.A. (2016, March 23). The Comparative Analysis of the Sports Fans Stereotypes in the Russian and Foreign Mass-Media. Retrieved from https://urgi.urfu.ru/fileadmin/user_upload/site_15503/Konvent/2016/Megaevents/Viktoriya_Dihor_Mega-Events_Conference_Ekaterinburg_2324_March_2016.pdf

Dihor V.A. (2015). The study of emotional reactions from football fans method of biofeedback training. Bekhterev and modern psychology of humanity: collection of articles of the $V$ international scientific-practical conference (to the 130th anniversary of the first Russian psychophysiological laboratory in Kazan), 514-519.

Dihor V.A., Burkova A.M., Gizullina A.V. (2017). Basics of football fans psychology. Retrieved from http://elar.urfu.ru/bitstream/10995/54023/1/978-5-7996-21971_2017.pdf

Dihor V. A., Gizullina A.V. The psychological aspect of the problem of football fanaticism. Retrieved from http://conf-v.narod.ru/Dix.pdf

Enikolopov S. N. (2010). Aggression and motivation of football fans. Kochenov readings. Psychology and law in modern Russia: Sat. theses of participants of the all-Russian conference on legal psychology with international participation, 27-28.

Il'in E. P. (2001). The structure of emotion as properties of the personality. Psychological problems of self-realization, 102-110.

Kozlov V. V. (2008). Fans. Past and present of Russian football, 360.

Mednikov S. V. (2011). Personal and situational prerequisites for aggressive behavior of football fans. Bulletin of St. Petersburg University. Episode 12: Psychology. Sociology. Pedagogy, 4, 152-163.

Update interim results of the study "2018 FIFA World Cup in the estimates and opinions of young people" (2017). Retrieved from http://www.ssarss.ru/index.php?page_id=19\&id=1452

Ribokas T. V. (2015). Genesis of the Russian fan movement and the tendency of forming the image of a football fan in our country. Sociodynamics, 12, 142-163. 